\title{
Kulak Defektli Hastaların Ekstraoral İmplant Ve Cad Cam Titanyum Altyapı İle Protetik Rehabilitasyonu: Vaka Serisi
}

\author{
Prosthetic Reconstruction of Patients with Auricular Defect Using Extraoral Implants and \\ CAD/CAM Titanium Frameworks: Case series.
}

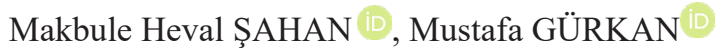

Öz

Kanser cerrahisi, doğumsal anomaliler, travma veya yanık sebebiyle meydana gelen kulak defektleri, hastanın yaşam kalitesini, psikolojisini ve sosyal hayatını olumsuz yönde etkilemektedir. İmplant destekli kulak protezleri maksillofasiyal defektli hastalar için önemli bir tedavi seçeneğidir. Günümüzde bilgisayar destekli tasarım ve bilgisayar destekli üretim sistemleri (CAD/CAM) ile implant destekli protezlere titanyum alt yapılar üretilmektedir. $\mathrm{Bu}$ vaka serisinin amac1, kulak protezlerinin retansiyon ve sağlamlığı için CAD/CAM sistemleri ile üretilen titanyum alt yapıların tedavisini değerlendirmektir. Ege Üniversitesi Dişhekimliği Fakültesi Protetik Diş Tedavisi Bölümü'ne kulak protezi yapımı için 10 hasta yönlendirildi. Klinik ve radyografik değerlendirmeleri yapıldıktan sonra uygun olan bölgelere ekstraoral implantlar yerleştirildi. 4 aylık iyileşme döneminden sonra ekstraoral implantların ölçüleri alındı. CAD/CAM sistemi ile titanyum alt yapıları üretildi. Barlar üzerine matriksler yerleştirildikten sonra silikondan kulak protezleri üretildi. Kulak protezi yapılan 10 hastanın 3 yıllık kontrollerinde titanyum alt yapılarda ve çevre dokularında herhangi bir yakınma ve klinik bulgu gözlenmedi. $\mathrm{CAD} / \mathrm{CAM}$ sistemleri titanyum alt yapıların daha dayanıklı, hassas ve tutucu olmasını mümkün kılmaktadır.

Anahtar Kelimeler: CAD/CAM, ekstraoral implant, kulak defekti

\begin{abstract}
Prosthetic Reconstruction of Patients with Auricular Defect Using Extraoral Implants and CAD/CAM Titanium Frameworks: Case series.

Auricular defects can occur because of trauma, congenital disorders, and ablative tumor surgery can vastly affect quality of life, psychology, and social behavior of the patient. Auricular

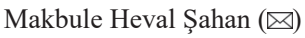

Department of Prosthodontics, Faculty of Dentistry, Ege University, Izmir, Turkey.

e-mail:hevalsahan@gmail.com

Mustafa Gürkan

Department of Prosthodontics, Faculty of Dentistry, Ege University, Izmir, Turkey.
\end{abstract}

Submitted / Gönderilme: 15.09.2020

Accepted/Kabul: 29.03.2021 prosthesis that are supported by extraoral implant is one of the most effective treatment. Nowadays, computer-assisted design and computer assisted machining (CAD/CAM) is being used the fabrication of implant-supported frameworks. The purpose of the case series was to evaluate the treatment of ten maxillofacial patients using $\mathrm{CAD} / \mathrm{CAM}$ copy-milled framework for retention and support of auricular prosthesis. 10 patients were referred to Ege University School of Dentistry department of prosthodontics for processing the auricular prosthesis. After the clinical and radiographic evaluation of the patients, extraoral implants were placed in the proper positions. After a four month healing period, an impression of the implant position was made using a dental impression material. The manufacture of the titanium frameworks were completed with the CAD/CAM system. Once the matrixes were placed on the titanium framework, silicone auricular epistheses were processed. During the control appointments after 3 years of the 10 patients, no discomfort or clinical inflamation at the titanium framework part or around the tissues were observed. It was concluded that the $\mathrm{CAD} / \mathrm{CAM}$ systems make the titanium frameworks become more precise, durable and retentive.

Keywords: Auricular defects, CAD/CAM, exrtaoral implants.

\section{Giriş}

Çene ve yüz bölgesi yapılarının bozukluk ve eksikliklerinde çene-yüz defektleri oluşmaktadır. Çeneyüz defektleri, kanser sebebi ile cerrahiler, konjenital (doğumsal) veya travmalar sonucu oluşabilir. Doğumsal ya da kazanılmış defektler nedeni ile sosyal ilişkilerde oluşan sinırlamalar, psikolojik sorunlar meydana getirmektedir. $(1,2)$

Kulak defektleri konjenital gelişim bozuklukları, travma veya tümör cerrahisi sonrası oluşabilir. Bu defektler, hastanın psikolojisini, sosyal hayatını ve yaşam kalitesini olumsuz yönde etkiler. Kulak defektlerinde tedavi seçenekleri; saç uzatma, otojen rekonstrüksiyon veya kulak protezleridir. Çene-yüz defektlerinin tedavisinde çeşitli mikrovasküler plastik cerrahi yöntemleri de uygulanmaktadır. Ancak bazı 
vakalar için uygulanan cerrahi yöntemler başarılı bir sonuç vermeyebilmektedir. $\mathrm{Bu}$ durumlarda, çene yüz protezleri, olumlu estetik sonuç verdikleri için iyi bir alternatiftir. $(3,4,5)$

Epitezlerin tutuculuğunu sağlamak için yardımcı araçlardan, anatomik oluşumlardan, adezivlerden ve ekstraoral implantlardan yararlanılır. Ekstraoral implantlar protezin tutuculuğunu ve stabilitesini artırır, doğru konumlandırılmasını sağlar ve kullanım ömrünü artırır. Ekstraoral implantların ayrıca estetiğin daha iyi sağlanması, demarkasyon hattının daha iyi şekillendirilmesi, adezivlerin kullanımının azaltılmasına bağlı olarak protez özelliklerinin korunması, yeterli tutuculuk sağlanarak hasta özgüveninin arttırılması ve adezivlerin cilde irritan etkisinin ortadan kaldırılması gibi önemli avantajları vardır. $(6,7)$

Çene yüz protezlerinde tutuculuk, bar, mıknatıs ya da bu iki ataçmanın birlikte kullanımıyla sağlanır. Küresel ataçman nadir olarak tutucu olarak kullanılır. Tutucu sistem seçiminde, implantın bölgesinde hareketli doku olup olmaması, dokunun kas aktivitesi, protezin rijitliği ve hastanın hijyeni sağlamadaki becerisi göz önüne alınır. (8)

80’li y1llardan günümüze gelişen endüstriyel teknoloji ile birlikte $\mathrm{CAD} / \mathrm{CAM}$ sistemleri estetik diş hekimliğinde kullanılmaya başlanmıştır. Inlay, onlay, laminate venerler, implant destekli protezlerde alt yap1 tasarımında kullanılabildiği gibi çene yüz protezlerinde de kullanılmaktadır. Anatomik özelliklere ve ten rengine uygun oluşturulan silikon kulak protezleri implantlara bar ya da magnet ile bağlanır. Hazır barlar ile hazırlanan alt yapılarda oluşan komplikasyonları engellemek için CAD/ CAM için üretilmiş titanyum bloklardan elde edilen barlar, kulak protezleri için iyi bir alternatif olmuştur. (9)

Olgu serisinde farklı sebeplerle kazanılmış kulak defektine sahip 10 hastaya uygulanan implant destekli kulak protezi için titanyum alt yapının üretimi ve klinik sonuçları tartışılmışıtır.

\section{Gereç ve Yöntemler}

Tüm kulak dokusunu kaybeden 10 hasta (1 kadın, 9 erkek) implant destekli kulak protezi yapımı için Ege Üniversitesi Diş Hekimliği Fakültesi Protetik Diş Tedavisi Anabilim Dalı'na başvurmuştur. Bu hastaların 2'si yanık, 2'si travma, 4'ü konjenital ve 2'si kanser cerrahisi sonucu kulak dokularını kaybetmişlerdir. Kulak protezi planlanan hastalara implant yerleştirilecek bölgelerinin kemik durumunu değerlendirmek için bilgisayarlı tomografi görüntüleri istendi. Tomografi sonucuna göre kemik dokusunun implant destekli kulak protezi için uygun olduğuna karar verildi. Uygulanacak olan tedavinin planı hastalara ve ailelerine anlatıldı. İmplantların uygun konum ve açıda yerleştirilebilmeleri amacıyla cerrahi stent hazırlandı. Cerrahi stent için hastanın operasyon sahasından irreversibl hidrokolloid ölçü maddesi (Ca37, Cavex, Haarlem, Hollanda) kullanılarak ölçü alındı. Sağlam kulak model alınarak kulak şeklinde akrilik stent hazırlandı. (Resim 1) İmplantların olması planlanan yerlere denk gelecek şekilde delikler açıldı. Operasyon sırasında hastanın implant uygulanacak bölgesine göre konumlandırıldı. (Resim 2) Her hastaya üçer adet ekstraoral implant (Institut Straumann AG, İsviçre) diş kulak yolunun arkasına bir ark oluşturacak şekilde yerleştirildi. 3-4 aylık bir bekleme süresi tamamlandıktan sonra ikinci aşama olan cerrahi işlem ile dayanaklar yerleştirildi. Dayanakların üzerine iyileşme başlıkları yerleştirildikten sonra kapatıldı.

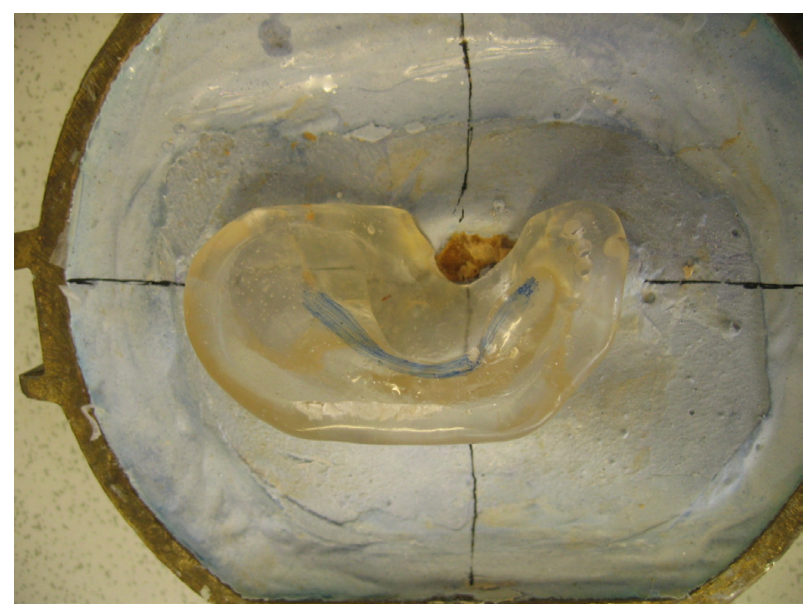

Resim 1. Kulak şeklinde hazırlanmış cerrahi stent

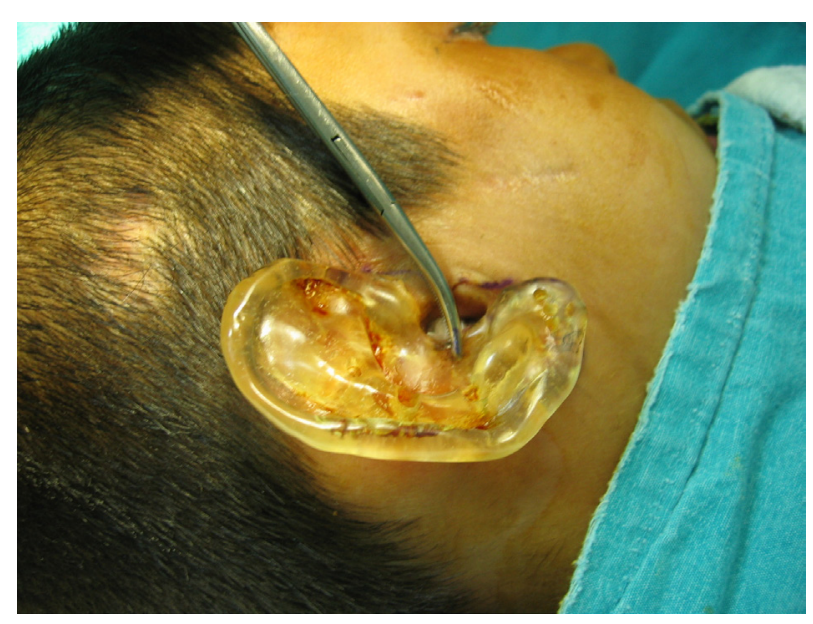

Resim 2. Cerrahi stentin operasyon sahasında konumlandırılmas1 
Ölçü alma işlemi implant çevresindeki yumuşak dokuların 1 haftalık iyileşme dönemi tamamlandıktan sonra, gerçekleştirildi. (Resim 3) Dayanakların üzerine ölçü parçaları (Institut Straumann AG, İsviçre) yerleştirilerek silikon esaslı ölçü maddesi (Speedex, Coltene/Whaledent, İsviçre) ile implantların ve defekt bölgesinin ölçüsü alındı. Alınan ölçüler üç boyutlu alt yapı tasarımı yapılması için laboratuvara gönderildi. Laboratuvarda planlaması yapılan titanyum alt yapılar dijital ortamda kontrol edildi.(Resim 4a, 4b) Tasarım ve kesim işlemi tamamlanan alt yapıların hasta üzerinde uyum provası yapıldı. (Resim 5) Prova yapılırken pasif uyuma ve bar ve dokular arasındaki mesafenin dokulara baskı yapmamasına dikkat edildi. İki dayanak arasındaki uzaklığa uygun olarak kesilen tutucu parçalar (Dolder bar matrix; Institut Straumann AG, İsviçre) bar üzerine yerleştirildi. Bar ve doku arasında kalan boşluklar alçı model üzerinde mum ile dolduruldu ve tutucu parçaları birleştiren akrilik rezin (Akribel; Atlas-Enta A.Ş, İzmir, Türkiye) alt yapı hazırlandı.

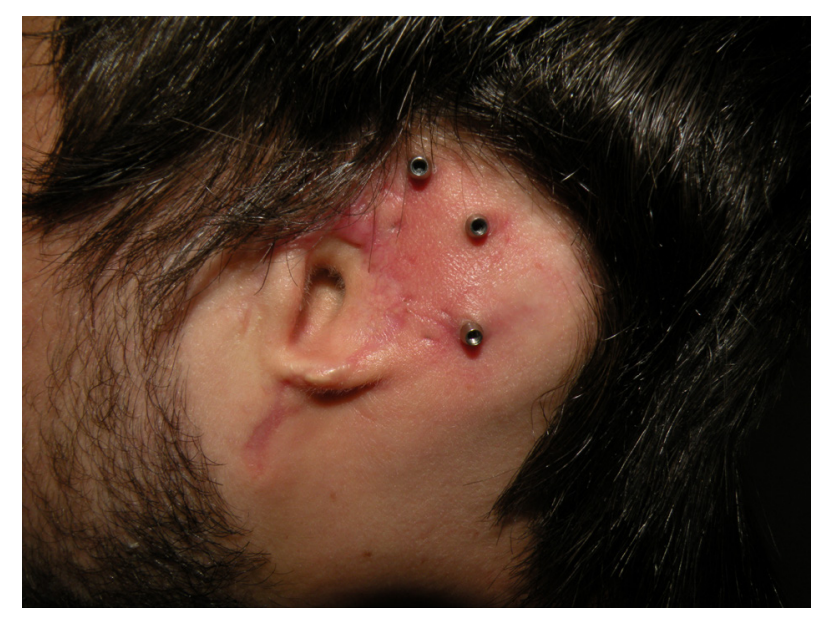

Resim 3. İmplant cerrahisi sonrası dayanakların yerleştirilmesi

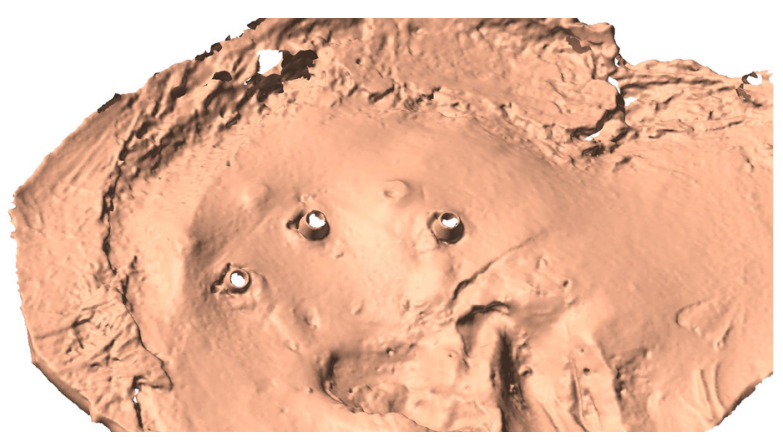

Resim 4a. Bilgisayar ortamında alt yapı tasarımı için alçı modelin taranmas1

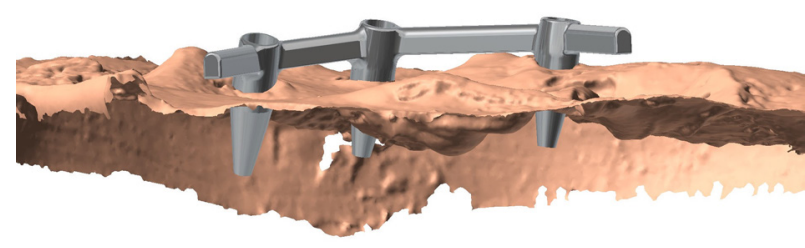

Resim 4b. Bilgisayar ortamında alt yapı tasarımının yapılması

Kulak modelajında kullanılmak üzere hidrokolloid ölçü maddesi (Ca37, Cavex, Haarlem, Hollanda) ile hastanın sağlam kulağının ölçüsü alındı. Alçı model üzerinde kulak protezinin mum modelajı sağlam kulağın şekline uygun olacak şekilde tamamlandı. Hasta üzerinde protezin mum örneğinin şekli, büyüklüğü ve pozisyonu sağlam kulağ1 rehber alınarak değerlendirildi. Son düzeltmeler yapıldıktan sonra laboratuvar aşamasına geçildi. Muflalama işleminde modelasyonun mufla kenarlarından eşit uzaklıkta olacak şekilde yeri ayarlandı. Kulak kepçesinin anatomik şekli sebebiyle alçı mufla 3 parça halinde hazırlandı. 3 parçalı mufla hazırlanarak hem renklendirilmiş silikonun kolaylıkla uygun bölgeye yerleştirilmesi hem de polimerizasyon sonrası kalıp bozulmadan protezin kolaylıkla çıkarılabilmesi amaçlandı. Muflalama işlemi tamamlandıktan sonra mum eritildikten sonra alçı kalıbın soğuması beklendi. Farklı bölgelere göre renklendirilmesi tamamlanan silikon (Cosmesil; Principality Medical Ltd, South Wales, UK), alçı mufla içine yerleştirildi. $100^{\circ} \mathrm{C}$ 'de 1 saat süre ile polimerize edildi. Hastanın ten rengine ve sağlam kulağının renk özelliklerine göre silikon intrensek olarak renklendirildi. Polimerizasyon tamamlandıktan sonra silikon mufla içinden çıkarıldı, fazlalıklar kesilerek uzaklaştırıldı. Bazı bölgelerde renk tonlarının ayarlanması için ekstrensek renklendirme yapıldı. Hasta, implant ve protez bakımı hakkında bilgilendirildikten sonra, hastaya protez teslim edildi. (Resim 6) Kullanıma alışma, renk stabilitesi, kenar uyumu ve protez bakımı yönünden ilk üç ay periodik kontrollere çağırıldı. 3 aylık yapılan kontrollerde kullanıma alışma, renk stabilitesi, kenar uyumu ve protez bakımı ile ilgili herhangi bir şikayet rapor edilmedi. Hastaların yıllık kontrollerinde CAD/CAM ile hazırlanan alt yapıların etrafındaki yumuşak doku ve implantlar değerlendirildi. 3 yıl sonunda yumuşak doku ve implantlarda herhangi bir bulguya rastlanmadi. 


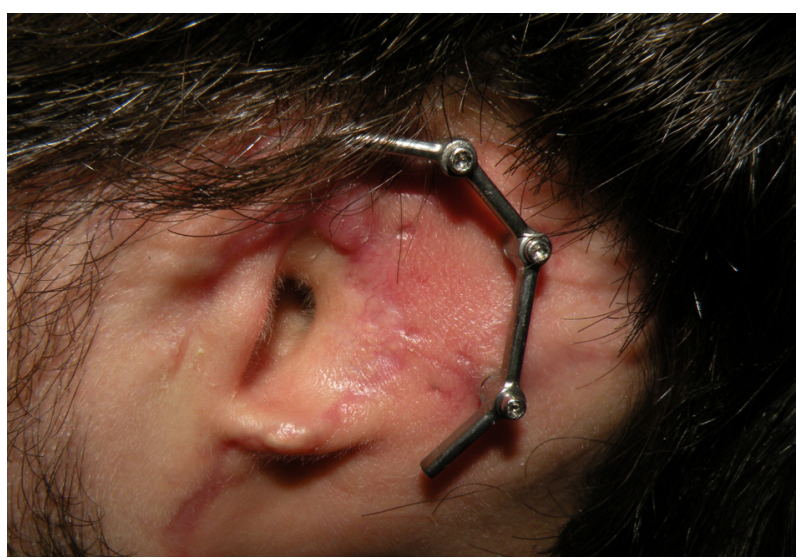

Resim 5. Titanyum alt yapının hasta üzerinde prova yapılması

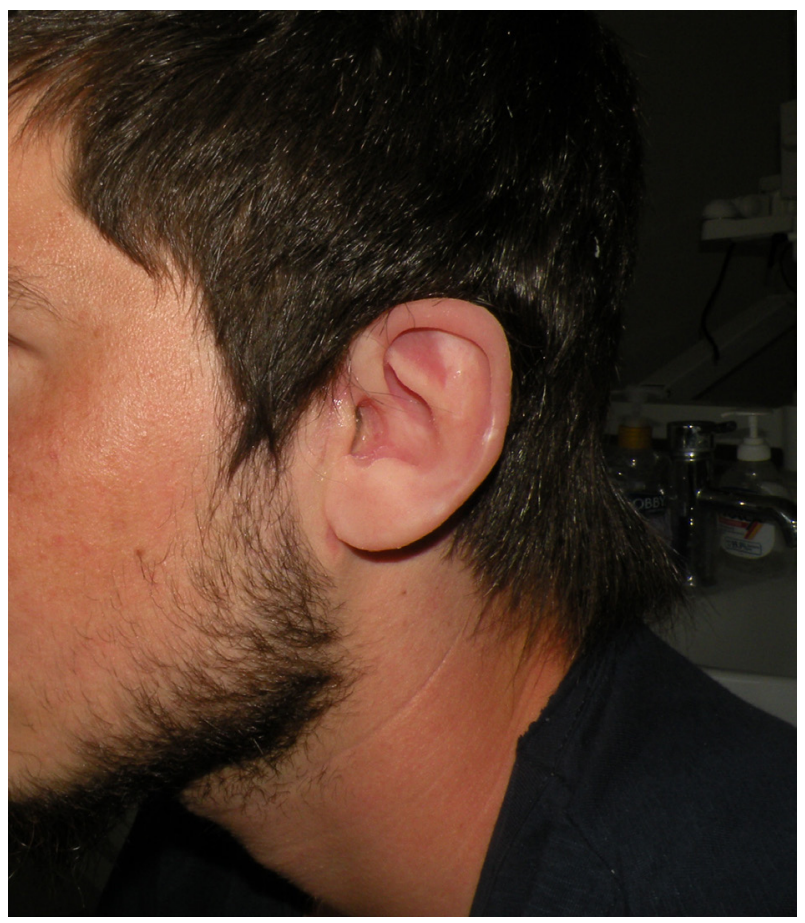

Resim 6. Hastaya kulak protezi uygulaması

\section{Tartışma}

Çene ve yüz bölgesi defektlerinin \%70'ini kulak defektleri oluşturmaktadır. Cerrahi işlem seçeneklerinin yetersiz kaldığı vakalarda, çene yüz protezleri kulak defektlerinin rahabilitasyonunda önemli bir rol oynar. (1) Çene yüz bölgesinin ilgilendiren defektlerde konumu sebebi ile kulak protezlerinin tutuculuğu önemlidir. Adeziv yapıştırıcılarla birlikte osseointegre implantların kullanımı hasta açısından büyük avantajlar getirmiştir. $(4,5,10)$
Ekstraoral implantların kulak protezlerinde kullanımıyla sağlanan tutuculuk avantajı, ilgili bölgede uygun kemik kalınlığı ve hacmiyle ilgilidir. Temporal kemik, genellikle 3-4 mm uzunluktaki bir implant için uygun kalınlığa sahiptir ve genellikle meatus acusticus externus çevresine 3-4 adet implant yerleştirilebilir. (11) Yapılan bu çalışmada hastalara 3'er adet ekstraoral implant yerleştirildi.

Nishimura ve arkadaşları kulak defekti olan 10 hastaya toplam 40 implant yerleştirmişlerdir. Hastaların 38 ay boyunca kontrol edildiği çalışmada başarı oranı \% 100 olarak bulunmuştur. (12) Wright ve arkadaşları da kulak defekti olan 16 hastaya toplam 39 implant yerleştirdikleri çalışmada, hastalar 6 ay-17 yıl boyunca kontrol edilmiş ve \% 100 başarı sağladıklarını bildirmişlerdir. (13) Yapılan çalışmada hastaların 3 yıllık takibinde herhangi bir implant kaybina rastlanmadi.

Curi ve ark yaptıkları çalışmada ekstraoral implant ve epitezlerin kullanım sürelerini değerlendirmişlerdir. 2 yıllık değerlendirme sonucuna göre nasal bölgedeki implantların oranı $\% 90.9$, protezin oranı $\% 90.4$. diğer yüz bölgesindeki implant ve protezlerin oranlarının benzer olduğu görülmüştür. Curi ve ark çalışmalarının sonuçlarına göre ekstraoral implantlarının kullanımının güvenilir ve uygun olduğu sonucuna ulaşmışlardır. (14) Yapılan çalışmada, kulak protezi yapılan hastaların implantlarında herhangi bir kayıp veya yumuşak doku irritasyonu görülmedi.

Karakoca ve ark yaptıkları çalışmada ekstraoral implantlarla ilgili sıklıkla karşılaşılan komplikasyon olarak bar klips sisteminde retansiyon kayipları, bar ve abutment vidalarında gevşeme ve silikon ve akrilik alt yapı ile arasında bağlantı kayıpları olduğunu bildirmişlerdir. Ancak bu komplikasyonlara rağmen cerrahi yöntemlerin kısıtll1ıkları sebebi ile ekstraoral implant kullanımının endikasyonunun uygun olduğu bildirilmiştir. (15) CAD/CAM sistemleri ile üretilen titanyum bar alt yapı ile klipsler arasında herhangi bir retansiyon kaybı gözlenmedi.

Hastaların defekt bölgesinden elde edilen manyetik rezonans (MR) ve bilgisayarlı tomografi (CT) verileri doğrultusunda, hızlı prototip üretim cihazları ile çene yüz protezlerinin üretimleri gerçekleştirilebilmektedir. Böylece ölçü almadan defekt bölgesiyle uyumlu, boyut, şekil ve estetik olarak uyumlu çene yüz protezleri üretilebilmektedir. $(16,17,18)$ Yapılan çalışmada CAD/CAM sistemleri protezin tutuculuğunu sağlayan alt yapının üretilmesi aşamasında kullanılmıştır. 
Konvansiyonel tekniklerle hazırlanan barlı üst yapılara göre $\mathrm{CAD} / \mathrm{CAM}$ sistemiyle hazırlanan tek parça titanyum barlar hafifliği, ekstraoral implantlar ile olan üstün uyumu, tek parça olması ve lehim barındırmaması, dayanımlarının fazla olması nedenleriyle günümüzde tercih sebebidir. Ağız içi implant üstü protezlerde günümüzde sıklıkla kullanılmaya başlanmış olan titanyum barların avantajları çene yüz bölgesinde de oldukça verimli sonuçlar alınmasını sağlamaktadır. Zor bir yapım sürecinden geçen çene yüz protezlerin kullanım ömrünü uzatmakta ve hasta memnuniyetini arttırmaktadırlar.

\section{Kaynakça}

1. Chang TL, Garrett N, Roumanas E, Beumer J. Treatment satisfaction with facial prostheses. J. Prosthet. Dent. (JPD). 2005; 94: 275-80.

2. Saraçoğlu B, Zulfikar H, Atay A, Gunay, Y. Treatment Outcome of Extraoral Implants in the Carniofacial Region. J. Craniofac. Surg. (JCS). 2010; 21: 751-8.

3. Nemli SK, Çağlar A, Sarısoy Ş. İmplant destekli kulak protezinde doku uyumunun sağlanmasi: Olgu sunumu. G.Ü. Diş Hek. Fak. Derg. 2010; 27(3): 201-6.

4. Atay A, Karayazgan B, Günay Y, Oruç S. Kulak protezi yapımı: farklı bir teknikle. Gülhane Med. J. 2009; 51: 122-5.

5. Atay A, Uzel G, Günay Y. İmplant destekli kulak protezi: Olgu sunumu. Gülhane Tip Derg. 2013; 55: 314-7.

6. Beumer j, Curtis TA, Marunick MT. Maxillofacial rehabilitation: prosthodontic and surgical considerations. St.Louis: Medico Dental Media Intl, 1996: 81-83, 444-9.

7. Roumanas ED, Freymiller EG, Chang TL, et al. Implant retained prostheses for facial defects: an up to 14-year follow-up report on the survival rates of implants at UCLA. Int. J. Prosthodont. (IJP). 2002; 15: 325-7.

8. Pehlivan N, Nemli SK, Karacaer Ö. Çene yüz protezleri ve ekstraoral implantlar G.Ü. Diş Hek. Fak. Derg. 2011; 28(2): 123-9.
9. Daniel S, Eggbeer D. ACAD and AM process for maxillofacial prostheses bar-clip retention. Rapid Prototyping Journal. (RPJ). 2016; 22(1): 170-7.

10. Gitto CA, Plata WG, Schaaf NG. Evaluation of the peri implant epithelial tissue of percutaneous implant abutments supporting maxillofacial prostheses. Int. J. Oral maxillofac. Impl. (JOMI).1994; 9: 197-206.

11. Jacobsson M, Tjellstrom A, Fine L,et al. A retrospective study of osseointegrated skin-penetrating titanium fixtures used for retaining facial prostheses. Int. J. Oral Maxillofac. Implants. (JOMI).1992; 7: 523-8.

12. Nishimura RD, Roumanas E, Moy PK, Sugai T. Nasal defects and osseointegrated implants: UCLA experience. J. Prosthet. Dent. (JPD). 1996;76: 597-602.

13. Wright RF, Zemnick C, Wazen JJ, Asher E. Osseointegrated implants and auricular defects: A case series study. J. Prosthodont. (JOP). 2008; 17: 468-75.

14. Curi MM, Oliveira MF, Molina G, et al: Extraoral implants in the rehabilitation of craniofacial defects: implant and prosthesis survival rates and peri-implant soft tissue evaluation. J. Oral Maxillofac. Surg. (JOMS). 2012;70:1551-7.

15. Karakoca S, Aydin C, Yilmaz H, et al: Retrospective study of treatment outcomes with implant-retained extraoral prostheses: survival rates and prosthetic complications. J. Prosthet. Dent. (JPD). 2010;103:118-126.

16. Feng Z, Dong Y, Zhao Y, Bai S, Zhou B, Bi Y, Wu G. Computer-assisted technique for the design and manufacture of realistic facial prostheses. Br. J. Oral Maxillofac. Surg. (BOMS). 2010, 48: 105-9.

17. Ciocca L, Scotti R. CAD-CAM generated ear cast by means of a laser scanner and rapid prototyping machine. J. Prosthet. Dent. (JPD). 2004, 92: 591-5.

18. Cheah CM, Chua CK, Tan KH, Teo CK. Integration of laser surface digitizing with CAD/CAM techniques for developing facial prostheses. Part 1: Design and fabrication of prostheses. Int. J. Prosthodont. (IJP). 2003;16(4):435-41. 